The United Nations
University

INTECH

Institute for New Technologies

Discussion Paper Series

\#9703

\title{
Technology Acquisition, De-regulation and Competitiveness: A Study of Indian Automobile Industry
}

\author{
K. Narayanan
}

September 1997

UNU/INTECH Discussion Papers intend to disseminate preliminary results of the research carried out at the Institute to attract comments. 


\title{
Technology Acquisition, De-regulation and Competitiveness: A Study of Indian Automobile Industry
}

\author{
K. Narayanan \\ Department of Economics, Kirori Mal College \\ University of Delhi and \\ Research Scholar, Institute of Economic Growth \\ Delhi 110007 \\ INDIA
}

Fax: 0091-11-7257410

E mail: Narayan@ieg.ernet.in

\begin{abstract}
This paper has attempted to analyse the effects of deregulation policy, introduced in India during the mid 1980s, on technology acquisition and competitiveness in the Indian automobile industry during the 1980s. Following evolutionary theoretical framework, the paper argues that asymmetry among firms in terms of technology acquisition explain much of the firm level differences in competitiveness.

Asymmetry in technology acquisition is largely due to differences in the firms' ability to bring about technological paradigm and trajectory shifts. The results of the econometric exercise support the view that, even in an era of capacity licensing, development of competitive skills crucially depended upon the ability to build specific technology trajectory advantages. This is achieved by successfully complementing imported technology with in-house technological efforts. Competitiveness in a deregulated regime would, however, depend upon the ability of the firm to bring about technological paradigm shifts. New firms who depended on intra-firm transfer of technology and firms with in-house R \& D efforts, to accomplish paradigm shifts, appear more successful. Furthermore, in a liberal regime, advantages of vertical integration also appear to be important determinants of competitiveness
\end{abstract}

This paper is part of the Ph.D. research work that 1 am doing in Delhi University. A substantial part of this work was carried out during my Internship at UNUANTECH, Maastricht under the supervision of Dr. Nagesh Kumar. 1 thank him for his useful comments and suggestions. 1 am grateful to my research supervisors Professors N.S.Siddharthan and K.L.Krishna for their valuable guidance. An earlier version of this paper was presented in a seminar at UNU/INTECH and 1 benefited from the observations made in the seminar by Professors Charles Cooper, Shulin Gu and Swasti Mitter. The error(s) that remain are my own. 


\section{Technology Acquisition, De-regulation and Competitiveness: \\ A Study of Indian Automobile Industry}

\section{Introduction:}

The objective of this paper is to examine the impact of the de-regulation policy, introduced in India during the mid 1980s, on the competitiveness of Indian Automobile firms. Specifically the study would attempt to answer the following question, namely: why do some firms perform well in terms of changes in the domestic market share while the others don't? Automobile industry in India was subjected to substantial policy changes in the $1980 \mathrm{~s}$ as a part of the economic liberalisation measures initiated by the government. The motive behind these changes was to bring in competitiveness through technological upgrading in an industry which has otherwise been enjoying a protected market. The study uses the evolutionary theoretical framework in the analysis of inter-firm differences in competitiveness. In particular the study focuses on the role of technological paradigm and trajectory shifts, product differentiation, and the de-regulation policy in the determination of inter-firm differences in competitiveness. This paper argues that asymmetry among firms in terms of technology acquisition [through technology imports and in-house efforts] explain much of the inter-firm variation in competitiveness.

The paper is organised as follows: Section 2 presents a brief history and structure of the Indian automobile industry. The relationship between de-regulation policy and technology paradigm and trajectory shifts is presented in section 3. Section 4 provides the hypotheses on the determination of Competitiveness. While section 5 presents the discussion on sample, data and the model, section 6 discusses the results of the study. Section 7 deals with summary and conclusion of the study.

\section{A Brief History and Structure of Automobile Industry:}

Automobile industry in India had been operating under the conditions of what is often termed as a "protected market' - protected both from internal and external competition, for a 
fairly long period. Investment behaviour of firms was characterised by the lack of competitive forces that could operate in the product market with the existence of excess demand conditions for a long period of time. The constraints were significant because of numerous entry barriers erected by the government through industrial licensing, import restrictions and other instruments. Entry barriers were operating not only with regard to new entrants but also in the case of existing firms because of restrictions on diversification, expansion of capacity, foreign technology collaborations, imports of capital stock and components. The impact of these restrictions were especially significant in this industry since most of the firms began their production process with technology imports. Moreover, the number of firms in various segments [sectors] of this industry, viz., Cars and other four wheeled drives [CARS], Light commercial vehicles [LCV1 and Medium and Heavy commercial vehicles $[\mathrm{HCV}]$, until the early eighties, were very few. In some products there were hardly one or two firms operating till the early 1980s [eg. CARS]. In the case of HCV there was no change at all in the number of units, with the same four firms producing the chassis. However, in the case of the ancillary sector, the production structure underwent a substantial change, thanks to the government policy of restrictions on imports of certain components and encouragement of the indigenous components.

It was observed [Narayanan 1988] that with the presence of an oligopolistic structure of this magnitude, most of the firms were enjoying large profit-margins, high growth rates and a large market share. There was little motivation for diversification and technological upgradation, and there was hardly any introduction of new products or new models involving technological up-gradation. However, substantial technological learning has taken place in some firms [especially Telco and BaJaj] in the process of indiginisation and as a part of their efforts to adapt their products to suit the local conditions.

Important changes in industrial policy in the form of deregulation in the licensing framework, broad-banding, capacity re-endorsement and liberalisation of controls and restrictions on clearances for foreign collaborations and imports of capital goods and components were introduced in India during the mid 1980s. Further, the governments' attitude 
towards foreign direct investment also underwent a significant change from a more suspicious policy which restricted the foreign investment possibilities to a more positive approach expecting them to play a crucial role in technological upgradation of Indian industry. Technological acquisition was expected to enable the industries to modernise and thereby improve their competitive capabilities. The de-regulation and liberalisation of mid-eighties resulted in the introduction of various new models of motor vehicles in collaboration with Japanese and Western auto manufacturers leading to a transformation of the structure that existed in this industry.

Automobile production in India increased substantially during this period [Table 1].

While the total motor vehicles production increased from 126 thousand in 1980-81 to 350 thousand in 1989-90, the Cars sector alone registered an increase from a mere 47 thousands to 224 thousand during the same period. The commercial vehicles [consisting of HCV and LCV1 production also increased from 79 thousand in 1980-81 to 125 thousand in 1989-90. However, within the Commercial vehicles segment, it is the LCV sector whose production increased more than 100 per cent during this period. The HCV sector also registered an increase, but relatively less than both the LCV and the Cars sector.

It is in this growth process that a change in the structure took place within the Motor Vehicles industry in India. The extent and nature of change was different in various segments of the industry depending upon the respective structures that existed before. It resulted mostly in the form of entry of new firms, diversification of the production and introduction of new products. While new entries were allowed by de-licensing, diversification was made possible through the increase in competition, as a result of entry, and the broad-banding scheme introduced by the government. In almost all the segments of this industry (except the HCV) there were entry of new firms. Entry and diversification in most cases were with the help of imported technology. There has also been a case of entry in the LCV by Telco, which was a result of their own in-house R \& D efforts. In the $\mathrm{HCV}$ sector, the competition strengthened between the two leading firms who preferred the market mode [licensing] for acquiring the latest technology configuration for certain components and parts. 
Technological up-gradation has also taken place with imports of capital goods (embodied technology). Entry of firms with the improved technology developed elsewhere forced the existing firms to bring about technological up-gradation with the fear of a reduction in their market share. Almost all the new entrants were with foreign equity participation.

Technology imports were more frequent and in a larger scale in those sub-sectors where the rate of entry was higher - within the automobile industry. The industry visualised a cut-throat competition in the form of the technology of the product marketed and price oriented. There were some exits as well.

An analysis of the competitiveness of firms in the motor vehicles industry in India [in terms of market shares - defined by the number of vehicles sold by firms in different categories [presented in Tables 2 to 411 reveal a significant change in the relative position of the old and pioneering firms since deregulation. This is especially true in the case of CARS and LCV.

Entry of firms with Japanese technology in this category drastically altered the relative position of all the firms. While most of the old firms were struggling to prevent a drastic reduction in their share, the new ones with the latest technology were trying to capture the market. Within this, Cars sector seem to have had a dramatic change in favour of the newly emerged firm Maruti. In the LCV sector though most of the new entries are with Japanese collaborations and have established a clear role in the market, Telco, which entered during 1984-85, cornered $30 \%$ of the market share by 1990. Telco's new product is the net result of its trajectory development and arms-length purchases of technology for components and parts. As a result the automobile industry of late has become much more diversified - with a broader technological base than it was before. Thus the policy changes of mid 1980s did much to shape the behaviour of firms - in terms of technological up-gradation, modernisation and the market structure.

\section{Liberalisation, Technological Paradigm and Trajectory Shifts:}

It is argued, in this study, that asymmetry among firms in terms of technology acquisition explain much of the inter-firm variation in competitiveness. Levels of technology acquisition is the end result of the nature of technological paradigms [workable design 
configuration which provides a framework] on which a firm operates and the type of problem solving trajectories that it adopts. While the nature of technological paradigm depends upon the mode of acquisition, firms manufacturing similar products adopt different methods of problem-solving activity and thereby bring about subsequent development and refinement of technology under use. They could also adopt different specific procedures [organisation of production, for example] and bring about improvements in them. Following Dosi [19881, it could be stated that any attempt to capture the effect of technological factors in determining competitiveness should take into account the existence of phenomena of interlinked technological trajectories and of various patterns of interaction between major technological systems or paradigms. Specifically, there are certain behavioural elements which yield to differences between firms in terms of innovative lags and leads, differences in costs of production, market pre-emption, etc. which form the basis for differences in competitiveness.

As has been stated before, in Section 2, Indian Automobile firms have grown within a closed environment. Strict capacity licensing and absence of competitive forces failed to provide incentive to the firms to bring about technological paradigm shifts. However, the highly inward looking and protectionist Indian environment has fostered a considerable amount of technological learning [Lall 19861. This technological learning is reflected in the indiginisation of the components and parts during the process of import substitution.

The policy changes introduced in India during the 1980s permitted the firms to bring about technology upgradation. Acquisition of technology through imports enabled the firms to shift to a different technology frontier. The shift is of various forms. It ranges from the beginning of production of a totally new product [for example Bajaj opted to manufacture a completely new LCV 'Tempo Trax' in 1987 with technical collaboration with Daimler-Benz and commissioned at a new plant] to the introduction of a differentiated product involving updated technology [for instance Pal's technical collaboration with Nissan of Japan for their A 12 engine and matching transmission enabled them to introduce an upgraded Premier car 118 NE in 19861. A change in the technology paradigm [shifting from one technology to the other] generally implies a change in the trajectories as well [Dosi 1988]. For example, Bajaj 
with the help of its learning process, introduced a new organisation of production in the new plant and developed rear-wheeled drive for Tempo Trax. Further, SMPL imported technology and production facilities from British Leyland and used its' in-house effort for design, development and tooling to introduce a new minibus. In other words, with different knowledge bases and different prototypes of artefacts, the techno-economic dimensions also vary. Since firms in this industry have acquired technology through different methods and from different sources, the degree of transfer of know-how could also vary. Archibugi and Michie (1995) reported that empirical results point to the competence of the partner rather than access to markets as the main determinant of transfer. Further, even if there are similarities in the technologies acquired, the problem-solving method [trajectories] adopted by firms varied. This can be seen in terms of the observed difference between firms which have imported technology from Japan and elsewhere. While the former went in for Japanese style of management and production [D'Costa, 1995], the later relied in adopting the imported technology in their own production line. Much of this asymmetry could be used to explain inter-firm variation in competitiveness. The influence is in the form of both a'product' effect [technological levels, quality, reliability of the products themselves] and a 'process' effect [where being early innovators firms are able to affect their costs through learning curves and also through among others the process innovations].

In sum it could be stated that massive inflow of technology and product improvement took place in this industry during the post liberalisation period. There were different forms of technology transfer and the degree of transfer varied across the mode and the competence of the recipient. Competence of the recipient depends on the level of accumulated technological capability through learning by doing and in-house $\mathrm{R} \& \mathrm{D}$ efforts. Moreover, the choice of different technological trajectories also influenced the capabilities in problem solving. It is important, therefore, to analyse the impact of de-regulation and technology acquisition in the determination of inter-firm variation in competitiveness. 


\section{Determinants of Competitiveness:}

Most of the empirical examination explaining competitiveness have focused their analysis to examine the relationship between technology variables and export performance [Posner 1961, Vernon 1966, Soete 1981, Dasgupta and Siddharthan 1985, Lall 1986, Kumar 1990, Dosi et al 1992, Willmore 1992 and Kumar \& Siddharthan 1994]. In the present study Competitiveness of a firm is defined in terms of the rate of change in market share. Firms in the automobile industry in India have been experiencing excess demand condition for a long time. This excess demand is largely due to strict capacity licensing followed by the Government. With de-regulation and relaxation of restriction on capacity, immediate attention of firms was to capture the local market. Moreover, as it is clear from the earlier analysis, entry of firms with the latest technology configuration brought about a change in the market share of the existing firms. It is therefore appropriate to use the rate of change in market shares of firms as a measure of competitiveness. This paper attempts to examine the factors that brought about this change in the market share. Specifically, the study explores the role played by technology acquisition, de-regulation, size of the firm, product differentiation, firms' age and vertical integration in determining inter-firm differences in competitiveness.

\subsection{Technology Acquisition and Market Share:}

The present study explores the relationship between technology acquisition and market share of firms under alternate policy regimes. Technology acquisition by a firm could be facilitated through imports [technology transfer from abroad] and in-house R\&D efforts.

Technology acquisition from abroad consists of technology imports through the market or "arms-length" purchase of technology against lump-sum and royalty payments [LRI], intra-firm transfer of technology through foreign direct investment (foreign equity participation [FE]) and technology transfer through the supply of machinery and equipment, where the technology is embodied in the imported capital good itself [MKI]. In-house research and development efforts of firms $[\mathrm{RDI}]$ is one of the important methods of location, adaptation, assimilation and development of the imported technology. 
Following Kumar \& Siddharthan [19941, it could be argued that firms in developing countries need to complement technology imports with in-house R \& D efforts. The need for this arises from the adaptation requirements of the imported technology to suit the Indian resource and market conditions. Cohen and Levinthal (1989) pointed out that firms invest in R \& D not only to pursue directly new process and product innovation, but also to develop and maintain their broader capabilities to assimilate and exploit externally available information. In the pre 1985 regulated regime, firms were not permitted to bring about technological paradigm shifts. Changes in product mix and manufacturing set up required obtaining fresh industrial licenses. However, given the technological paradigm, firms were allowed to traverse different trajectories. As a result, most of the technology imports were mainly to bring about incremental changes in the products or processes. In-house R \& D was essential to modify the imported technology and accomplish the trajectory shifts. Consequently in-house $\mathrm{R} \& \mathrm{D}$ efforts were basically aimed at adaptation requirements. As a result, technology imports, in the absence of in-house R \& D efforts, and in-house R \& D efforts, without technology imports, would both be inadequate to influence shifts in technological trajectories. The interaction between technology imports and in-house R \& D efforts alone can facilitate trajectory shifts. It is this successful adaptation of the imported technology and establishment of specific trajectory advantages which will enable the firm to build competitive capabilities. The present study, therefore, postulates that the interaction between various modes of technological imports and in-house R \& D efforts [FER, LRR \& MKR] would determine positively inter-firm variation in competitiveness during the pre de-regulation period. However, the variables capturing technology imports [viz., LRI, FE, and MK11 may not, individually, emerge significant in the determination of competitiveness in the absence of in-house R \& D efforts. On the contrary, under certain circumstances, in the presence of a very strong complementarity, some of their individual coefficients may even end up with a negative sign.

However, with liberalisation of restrictions on entry, capacity creation, product diversification and technology imports, firms were allowed to bring about technological paradigm shifts. These paradigm shifts have been facilitated by intra-firm transfers of technology through equity participation, imports of technology from the market and imports of 
capital goods. Paradigm shifts enable the firms to operate on a different technology frontier with which they can produce new and differentiated products. Since the existing trajectories were developed on the basis of the earlier paradigm, a change in the paradigm could make all the trajectory advantages that the firms had established so far redundant. In-house R \& D efforts, used to traverse trajectories, will not be of any use in the changed circumstances. Since technology imports after de-regulation are mainly to accomplish paradigm shifts, the relationship between imports of technology and in-house R \& D could even become from one of complementarity to substitution. As a result, the interaction variable would be inversely related to market competitiveness. In-house R \& D efforts, which had so far been used to adapt the imported technology and facilitate trajectory shifts, will now be directed mainly to locate their technology imports. Technology variables [LRI, FE, MKI and RDI], independently, would emerge positive and significant in determining competitiveness as they facilitate paradigm shifts.

\subsection{Skill Intensity:}

Accumulation of technological capabilities through learning by doing is also facilitated by the skilled manpower employed in a firm [SKILL]. The literature on technological capabilities in developing countries suggests that the capability of a firm to undertake efficient technological activities to develop competitiveness depends on its stock of skills [Cooper 19911. Technological change could also be brought about by efforts on production engineering, quality control, trouble shooting and shop floor management [Katz 19841. These forms of technological trajectories are attempted with the help of skilled manpower. With paradigm shifts and the subsequent changes in trajectories, advantages of technological capabilities through the learning process enable the firms to solve the problems. The result of this effort could be in the form of both a product and process effect. Inter-firm variation in skill formation, therefore, explain inter-firm differences in competitive performance.

\subsection{Product Improvements through imports of Components:}

Technology transfer in the form of a 'package' entail imports of components and spares for the recipient firms. Imports of components could also be due to certain costs and quality 
advantages. Prior to the introduction of the de-regulation policy, imports of components were used by the firms as a source of technological upgradation of their product. As a result, inspite of pressures on indiginisation, use of imported components and spares was not uncommon.

With liberalisation one would expect the imports of components to rise. However, the role of components import in determining the competitiveness of firms need not increase. This is because, with de-regulation, firms have the option of encouraging parallel technology transfer to component manufacturers as well. The study, therefore, postulates a positive role for product improvements through imports of components [MC1] in both the periods in the determination of competitiveness of firms.

\subsection{De-regulation:}

As has been pointed out earlier, the de-regulation policy introduced by the government during the 1980s had a significant impact in the form of an increase in technology inflow through various modes. Automobile manufacturing firms in India have been operating under a protected market with numerous restrictions. These restrictions provided no motivation or incentive for a firm to bring about technological upgradation. Moreover, capacity licensing restricted the firms from enjoying scale advantages. Accumulation of technological capability has been taking place mostly through the adaptation of specific technological trajectory and learning by doing in the process of indiginisation of production. The effect of policy change is in the form of a shift in the technology frontier as well as changes in the technological trajectories. While the shifts in technology frontiers were generally through acquisition from abroad, changes in the trajectories took the form of formal $\mathrm{R} \& \mathrm{D}$ and problem solving exercises. These shifts and changes were necessitated by the introduction of a competitive atmosphere. De-regulation enabled the firms to acquire the latest technology to produce a modernised product and thereby appropriate certain cost and technology specific advantages.

Government policy measure, as a result, influences the competitiveness of firms through its effect on technological efforts. 


\subsection{Firm Size:}

Following Schumpeter [19431, economics of scale [measured by firm size] could be said to influence technological efforts of a firm. Large sized firms in this industry, with their expertise over a period of time, may have a wider scope to go in for technology frontier shifts than their smaller counterpart. Further, economies of scale could enable a firm to have a greater degree of manoeuvrability in the technology under use through various problem solving trajectories and thereby acquire competitive advantages. However, the scope for improvement in market share for these large sized firms may be highly limited. Moreover, with deregulation, new firms with technologically upgraded product [acquired through foreign equity participation] might be more competitive than the older ones during this period. The exact nature of effect of this variable [SIZE] is therefore difficult to predict. Empirical findings on the relationship between size of the firm and export competitiveness has been mixed [Hirsch and Adar 1974, Gleijser 1980, Lall 1986, Kumar 1990, Willmore 1992, Bonaccorsi 1992 and Kumar and Siddharthan 1994].

\subsection{Product Differentiation:}

Competitiveness through shifts in technological paradigm and trajectories would also depend upon levels of product differentiation (represented by advertisement intensities) and age of the plant and machinery. Willmore (1992) argued that since advertising is associated with monopolistic competition, firms in monopolistic competition have an advantage because they operate on the declining portion of their average cost curve. In a particular industry study advertising could be used to capture the marketing efforts or market orientation of the firm.

Technology transfer generally involves the transfer of brand names and goodwill of the transferor, advertisement and sales promotion become an essential pre-requisite for marketing the produce. However, since most of the multinational firms which had set up plants jointly with their Indian counterpart in this industry are well established and have a large advertisement network on their own, advertisement intensity of the Indian firms may be an insignificant proportion to influence competitiveness. The study examines the role of advertisement intensity [ADI] in the determination of competitiveness. 


\subsection{Firm's Age:}

Age of the firm, measured in terms of the age of the plant and machinery, following Lall (1986) could be used as a crude and general proxy for learning. Moreover, age of the firm would also enable the firm to have an expertise in the manufacture of the product and thereby influence their ability to choose the mode and the nature of technology to be acquired from abroad. Accumulation of technology over a long period of learning process would also give the firm a comparative advantage over the new entrant. However, in a deregulated regime, emergence of new firms with the latest technology configuration from abroad and adaptation of the appropriate trajectories could alter the situation. Though new firms, mostly with intra-firm technology transfer, could bring with it the learning effect of the technology supplier, local firms with their accumulated 'learning-by-doing' could be in an advantageous position. The study postulates a positive role for the AGE variable throughout the period.

\subsection{Vertical Integration:}

The study also explores the role played by the degree of vertical integration in the determination of inter-firm differences in competitiveness. Following Williamson [1985] it could be stated that vertical integration takes place in order to economise on transaction costs.

Though automobile firms in India have been characterised by high degree of vertical integration, studies have pointed out a trend towards sub-contracting [Narayana 1989]. There always exist a trade off between specialisation and certainty. With the growth in specialisation and diffusion of skills, as reported by the earlier studies, the production cost penalty of vertical integration could increase. Moreover, with the availability of large number of suppliers and experience, the transaction cost advantage of vertical integration may also decline. However, there could be large scale variation across the firms within an industry. Kathuria [1996] found production organisation [vertical integration] to be a very important factor explaining the observed differences in technological capabilities of firms in the Indian Commercial Vehicles industry. This is because of the possibilities of transactions in technology and innovation results within a vertically integrated firm. Advantages of producing diverse components/parts of the vehicle themselves would enable a vertically integrated firm [V1] to ensure quality.

However, the role played by vertical integration in determining competitiveness is not resolved 
clearly. For instance, Japanese firms emphasise on lean manufacturing system in order to stay competitive and most of the new firms were with Japanese collaborations. It is therefore difficult to predict the exact nature of the impact of this variable in the determination of competitiveness.

\section{Sample, Data and the Model:}

The study uses data from the annual reports and balance-sheets of individual companies. The data set contains firm level data for 12 automobile manufacturing companies for the period 1980-81 to 1989-90. The data relate to firms assembling or producing cars and other four wheeled drives, light, medium and heavy commercial vehicles. The nature of the markets is different for these products. For example, while the cars and four wheeled drives are meant for personal use, light, medium and heavy commercial vehicles are all meant for commercial purposes. The study classified the motor vehicle firms in terms of CARS and Commercial Vehicles sectors and analyses competitiveness in both these segments of the Automobile industry in India.

For the empirical analysis, the observations for ten years namely $1980-81$ to $1989-90$ were pooled. Government of India took major decision to liberalise the economy and de-license Indian industry in 1985. There are year-to-year changes in the sample set due to the entry and exit of firms. This is especially after the policy year 1985-86. The study examines the impact of de-regulation with the help of slope dummy variables. Slope dummies were used because, with de-regulation, different firms have gone in for various modes of technology acquisition and the slope coefficients represent the effect of their respective technology variables. Intercept dummy, on the contrary, would capture the overall differences, if any, between these two time periods. Moreover, the study introduced slope dummy variables for all the explanatory variables for the post de-regulation period in order to examine the effect of government policy in the determination of inter-firm differences in competitiveness.

Competitiveness of firms is defined in terms of rate of change in the market share of a firm. Market share of a firm is estimated by taking the ratio of the annual sales turnover of a 
firm to that of the total sales of all the firms in that sector. Sales turnover, rather than the number of vehicles sold is used because of large scale differences between vehicles manufactured by these firms, which may not be strictly comparable. The empirical specification of the testable model being:

RMS = f(SIZE, VI, ADI, RDI, LRI, FE, MKI, MCI, SKILL, AGE, FER, LRR, MKR)

where

RMS - rate of change in market share defined as

$$
R M S=\frac{M S,-M S 1-1}{M S 1-1}
$$

MS - Market Share is defined in terms of the annual sales turnover of a firm to that of the total sectoral sales [viz., CARS and Commercial vehicles].

SIZE - size of the firm measured by the log value of annual sales turnover.

VI - degree of vertical integration defined by value added as a proportion of annual sales turnover ADI - Advertisement intensity defined by expenditure on advertisement and sales promotion as a proportion of sales

RDI - R \& D intensity measured by research and development expenditure as a proportion of sales LRI - Disembodied technology imports measured by lumpsum and royalty payments as a proportion of sales

FE - Degree of foreign ownership represented by proportion of value of equity of shares held by foreign firms to the total paid up capital of the firm

MKI - Embodied technology imports measured by value of imports of capital goods as a proportion of sales

MCI - Imports of components measured by the value of imports of components as a proportion of sales 
SKILL - Skill content of the workforce defined by the wages and salaries paid to the highly paid staff as a proportion of the total wage bill of the firm

AGE - Age of the firm measured by depreciation as a ratio of gross block

Interaction variables:

FER - FE(*)RDI

LRR - LRI $(*)$ RDI

MKR - NIKI (*) RDI

Variables ending with "D" are Slope dummy variables obtained by multiplying the dummy factor [0 for all observations prior to de-regulation and 1 for the post de-regulation period] by the respective variables.

The study uses Ordinary Least Square estimation to analyse the determinants of interfirm differences in the dependent variable, namely, the rate of change in market share. The results are corrected for potential heteroscedasticity, using White's consistent estimator method [the use of this method to correct for the possible presence of heteroscedasticity is given in Green 1993].

\section{Empirical Results:}

The results of the empirical analysis are presented in table 5. The coefficients and the $t$ values are presented in two separate columns for two sets of equations. While the first equation presents the results of the entire model, in the second equation SKILL variable was dropped as it did not turn out significant. In the empirical analysis two sector specific dummy variables [DCAR and DCOM] were introduced in order to control for differences between the sectors within the motor vehicles segment of the Indian automobile industry. However, since the results were similar they are not reported separately. All the results presented in the table deal with the determinants of inter-firm differences in rate of change in market share in the Motor vehicles industry, that is the two sectors defined earlier, taken together. Since the calculation of growth rates require one period lag, the number of observations are one set less than the sample period. 
The results are presented in two blocks - the first one dealing with all the explanatory variables and second the slope dummies. The t values for slope dummy variables relate to

significance of difference in the coefficient. The sign and coefficient of variables with significant $t$ values in both the periods are presented separately in Table 6 . The coefficient values and signs for post reform period are corrected by adding the coefficient values of variables with that of the slope dummies. This table facilitates comparison of results for pre and post de-regulation period. The findings of the study are discussed below.

In both the equations major variables capturing technological paradigm and trajectory shifts emerged very important in the determination of inter-firin differences in competitiveness. As hypothesised, the difference in the role played by technology variables between the two policy regimes is also well highlighted by the results. Further, more than the technology acquisition from abroad, the interaction between imported technology and in-house R \& D effort seems to be the most important determinant of competitiveness. In the period prior to de-regulation, two of the three interaction variables namely LRR and MKR emerged statistically significant with positive signs in both the equations. Three variables capturing technology imports [LRI, FE, MK11 emerged significant with negative sign for this period.

Whereas the in-house R \& D intensity, though also had a negative sign, did not turn out statistically significant. This result reiterates the strong complementarity between R \& D and technology imports and the need for efficient adaptation requirements of the imported technology to suit the local resource conditions. In an era of controls and regulations, technology imports were basically used to bring about incremental changes in products or processes. Therefore, imports of technology alone cannot facilitate technological trajectory shifts. This is the reason why all the three technology import variables emerged significant with a negative sign. In-house R \& D turned out insignificant because it, on its own, would also be inadequate to bring about trajectory shifts. It is the interaction between technology imports and in-house efforts that alone can accomplish trajectory shifts. Successful adaptation of the imported technology through in-house efforts and establishment of trajectory advantages were being used by the firms to build up competitive capabilities. This is the reason why two 
out of three interaction terms emerged significant with a relatively high positive coefficient value. Finns with foreign equity participation appear to be an exception to this.

However, as it is clear from the slope factors, all the technology variables capturing paradigm shifts [except FEI emerged very important in the post de-regulation period with a positive and highly significant coefficient. In the case of FE the co-efficient took a positive sign but with low $\mathrm{t}$ value. This result supports the contention that in a more liberal regime firms would prefer to import technologies to accomplish paradigm shifts. In-house R \& D, which was used to traverse different trajectories on an earlier paradigm, need to re-orient itself in these circumstances. Large Indian firms like TELCO used in-house $\mathrm{R} \& \mathrm{D}$ to facilitate paradigm shifts in the post reform period. In-house R \& D is also now directed by many firms to locate their technology imports. This could be the reason why RDI emerged significant with a positive coefficient. This in turn would imply that, during the period immediately after liberalisation, the relationship between imports of technology and in-house R \& D efforts [which has for long been complementary] turned out to be one of substitution. Further, two of the three interaction variables emerged significant [LRRI) and MKRDI with a negative sign in both the equations. This result also reiterates the competitive nature of technology imports and in-house efforts in facilitating paradigm shifts in a more liberal regime. The interaction factor for firms with foreign equity for this period also turned out positive but insignificant, thus pointing that they could be different. These firms which went in for intra-firm transfer of technology could also benefit from the successes of the technological efforts of the collaborators. This would imply that firms which brought about technology paradigm shifts through acquisition from abroad or relied on their in-house efforts for it were more competitive in the post de-regulation period.

Product improvements through imports of components turned out to be a very important factor in the determination of RMS in the pre de-regulation period. This is because imports of components was relatively not uncommon in this sector in India and firms used this as an alternative to indigenous technological development. However, with de-regulation and relaxation of restrictions on imports of technology [embodied and disembodied], firms 
preferred to import the designs to produce the technologically upgraded component rather than the component itself Moreover, some of the new firms [especially the ones with equity participation from Japan] went in for vendor development [whereby they encouraged parallel transfer of technology from the component suppliers of the parent firm to their counterpart in India]. This is perhaps the reason why MCI turned out significant with a lower coefficient value [implying a reduced role] during the post de-regulation period.

ADI emerged with a positive sign [though insignificant] in both the equations for the pre de-regulation period. However, the reverse turned out to be case [negative in both, though significant in only the second] in the post de-regulation period. This is because firms were issued specific product licenses and were not allowed to make any alteration in them until the mid eighties. One hardly noticed diversified products in the market. In the post reform period, most of the multinational firms which had set up plants jointly have a wide network and the advertisement intensity of the Indian firms may be too insignificant a proportion to influence their competitiveness. Though, gradually, the sign of advertisement may change with more intensive product competition.

Age of the firm turned out significant with a negative sign in both the periods. Since most of the old firms have a large market share, they may not be able to grow at a higher rate. Inability of the older firms to update their product in the pre de-regulation period could also be a possible explanation for this. Moreover, the learning effect seems to have been captured by the interaction factors themselves rather than the AGE. However, AGE emerging significant with a negative sign and a higher coefficient value in the post de-regulation period imply that new firms are growing faster than the older ones.

Firm size comes up with a negative sign in both the equations for the pre de-regulation period [significant in one]. There seems to be an inverse relationship between size of the firm and RMS. A possible explanation to this could be that smaller firms are as dynamic as their larger counterparts in building technological trajectory advantages. With de-regulation, the importance of firm size in determining the growth of market share seems to have reduced [Size 
did not turn out significant, though it has a negative sign]. The relationship between firm size and competitiveness is complex one. The literature using the Marris model of growth either did not find size to be important [Buckley et al 19781 or reported an inverse relationship between size and growth [Siddharthan and Lall 19821. However, in most of these studies size was a catchall variable. Siddharthan et al (1994), after introducing technology and other related factors along with the size variable, found firm size to be unimportant in explaining growth of large Indian firms. Since competitiveness is measured in terms of rate of growth in market share, the result correspond to that of the growth literature.

Vertical integration [V11 emerged significant with different signs in the determination of RMS over the two policy regimes. The negative sign for the first period could be due to the decline in the transaction cost advantage of vertical integration. The decline in the transaction cost is due to the increase in the number of suppliers of components and parts. This is in line with the findings of earlier studies which point towards the emergence of sub-contracting.

With de-regulation, however, foreign firms with an objective of capturing the market with technologically superior and guaranteed quality vehicles would choose to produce most of the components in-house. This could be because of the tacidity involved in the transfer of technology and innovation results and placing different engineering process under check.

The results imply that prior to the introduction of policy changes, while obtaining the license to manufacture would ensure a market share, maintaining a certain rate of growth in it depended upon successful adaptation and establishment of specific trajectory advantages. All other factors, other than obtaining the license and building trajectory advantages were unimportant in the determination of competitiveness. However, with the introduction of deregulation and de-licensing, threat of decline in the market share forced the firms to go in for technology paradigm shifts and introduce new products with technological up-gradation. This is clearly evident from the results where all the technology variables emerged significant with a positive sign in the determination of RMS in the post de-regulation period. 
These results, hold true for both the sub-sectors manufacturing commercial vehicles and cars in India. It, thus, support the argument that inter-firm differences in competitiveness depend crucially on shifts in technology paradigm and trajectories along with the degree of vertical integration, and levels of product quality improvements, which were made possible by the de-regulation policy in the Motor Vehicles sector of the Indian Automobile Industry.

\section{Summary and Conclusions:}

This paper has attempted to analyse the determinants of inter-firm differences in competitiveness in the Indian automobile industry during the 1980s. The study used the evolutionary theoretical framework to explain the competitiveness of the auto manufacturing firms in India. It is argued that asymmetry among firms in terms of technology acquisition explain much of the firm level differences in competitiveness. The firms are likely to achieve competitiveness through successful adaptation and building up of specific trajectory advantages. With de-regulation, however, the ability to bring about technology paradigm and trajectory shifts through acquisition from abroad or through in-house technological efforts and the resultant product quality development would explain inter-firm differences in competitiveness.

The results of the estimated model support the view that inter-firm differences in competitiveness in this industry in India are determined by variables capturing technology paradigm and trajectory shifts. The results also show that, even in an era of capacity licensing, development of competitive skills crucially depend upon the ability to develop specific technology trajectory advantages through successfully complementing imported technology with in-house technological efforts. Competitiveness in a de-regulated regime would, however, depend upon the ability of the firm to bring about technological paradigm shifts.

This is especially because of entry of new firms and the introduction of new models of vehicles involving technological upgradation. Absence of incentives to be innovative in a protected market also resulted in the sudden rush towards import of technology with de-regulation to bring about paradigm shifts. Different forms of technology transfers brought with it the know- 
how of the successes of technology suppliers. However, foreign firms which are successful in exploiting the internalisation advantages appear to be growing at a faster rate than the others.

The importance of vertical integration in the determination of competitiveness is well highlighted by the results. This is largely due to the tacitness in the transfer of technology and maintenance of product quality which foreign firms are likely to insist with equity participation. Finn size and competitiveness emerged with inverse relationship prior to reforms implying that small firms, with their dynamism and ability to adopt, would have a comparative advantage over their larger counterpart with the introduction of automation and flexible system of management. Size no longer seems to be influencing market share changes.

The relationship between product differentiation and competitiveness changed substantially between the two policy regimes, which is because one hardly witnessed introduction of any new product with technological upgradation before the policy changes and also all the firms were issued product specific licensing. However, after de-regulation, and specifically after the introduction of the broad-banding scheme, the number of vehicle producers increased substantially. More intensive product competition, which one has witnessed in India during the recent times, might assign a positive role for product differentiation in determining competitiveness. 
TABLE: 1 TRENDS IN MOTOR VEHICLES PRODUCTION IN INDIA

(in numbers)

\begin{tabular}{|lccc|}
\hline SECTORS & $1980-81$ & $1984-85$ & $1989-90$ \\
\hline CARS & 46942 & 99304 & 223587 \\
$\begin{array}{l}\text { COMMERCIAL VEHICLES } \\
\text { of which }\end{array}$ & 79174 & 966041 & 25051 \\
$\begin{array}{l}\text { Medium \& Heavy CVs } \\
\text { Light CVs }\end{array}$ & 58836 & 62626 & 76594 \\
\hline TOTAL & 20338 & 33978 & 48457 \\
\hline
\end{tabular}

Source: ACMA, Automotive Industry of India: Facts and Figures, various issues.

\begin{tabular}{|l|r|r|r|r|r|r|}
\hline \multicolumn{7}{|c|}{ TABLE: 2 } \\
\hline \multicolumn{7}{|c|}{ MARKET SHARE OF FIRMS IN THE HCV SECTOR } \\
\hline FIRMS & 1981 & 1983 & 1985 & 1986 & 1988 & 1990 \\
\hline ASHLEY & 24.94 & 23.16 & 23.48 & 27.59 & 26.56 & 27.21 \\
\hline HMOTOR & 2.06 & 0.57 & 1.14 & 1.33 & 0.00 & 0.00 \\
\hline PREMIER & 3.47 & 0.97 & 0.56 & 0.08 & 0.00 & 0.00 \\
\hline TELCO & 69.53 & 75.29 & 74.83 & 71.00 & 73.44 & 72.78 \\
\hline TOTAL & 100.00 & 100.00 & 100.00 & 100.00 & 100.00 & 100.00 \\
\hline Source: ACMA, Automotive Industry of India: Facts and Figures, Various issues. \\
\hline
\end{tabular}




\begin{tabular}{|l|r|r|r|r|r|r|}
\hline TABLE: 3 \\
\hline MARKET SHARE OF FIRMS IN THE LCV SECTOR \\
\hline FIRMS & 1981 & 1983 & 1985 & 1986 & 1988 & 1990 \\
\hline BAJAJ & 36.00 & 34.47 & 41.09 & 35.11 & 33.94 & 30.73 \\
\hline DCMTOY & 0.00 & 0.00 & 2.98 & 6.58 & 7.60 & 6.95 \\
\hline HMOTOR & 11.51 & 6.40 & 4.57 & 4.89 & 2.21 & 1.37 \\
\hline MAHINDRA & 29.03 & 36.84 & 32.25 & 27.91 & 11.70 & 9.12 \\
\hline ASHLEY & 0.00 & 0.00 & 0.00 & 0.00 & 0.16 & 0.46 \\
\hline EIMOTOR & 0.00 & 0.00 & 0.00 & 1.71 & 9.50 & 8.81 \\
\hline SWA MAZ & 0.00 & 0.00 & 0.00 & 4.42 & 4.67 & 6.31 \\
\hline TELCO & 0.00 & 0.00 & 0.00 & 8.25 & 24.71 & 30.69 \\
\hline PREMIER & 5.00 & 2.81 & 0.58 & 0.14 & 0.00 & 0.00 \\
\hline SMOTOR & 18.45 & 19.48 & 13.48 & 7.43 & 0.62 & 0.00 \\
\hline MAHNISSAN & 0.00 & 0.00 & 3.23 & 3.56 & 4.88 & 5.54 \\
\hline TOTAL & 100.00 & 100.00 & 98.17 & 100.00 & 100.00 & 99.98 \\
\hline Source: ACMA, Automotive Industry in India: Facts and Figures, Various issues & & \\
\hline
\end{tabular}

\begin{tabular}{|c|c|c|c|c|c|c|}
\hline TABLE: 4 & & & & & & \\
\hline MARKET SH & RE OF F & N THE C & CTOR & & & \\
\hline FIRMS & 1981 & 1983 & 1985 & 1986 & 1988 & 1990 \\
\hline SMOTOR & 0.01 & 0.00 & 0.01 & 1.15 & 0.15 & 0.00 \\
\hline HMOTOR & 41.95 & 40.15 & 19.11 & 16.25 & 14.15 & 12.43 \\
\hline MARUTI & 0.00 & 0.00 & 40.08 & 44.82 & 51.62 & 53.50 \\
\hline MAHINDR A & 22.15 & 25.64 & 16.93 & 18.47 & 14.99 & 13.92 \\
\hline PREMIER & 35.89 & 34.21 & 23.88 & 19.31 & 19.1 & 20.15 \\
\hline TOTAL & 100.00 & 100.00 & 100.00 & 100.00 & 100.00 & 100.00 \\
\hline
\end{tabular}




\begin{tabular}{|c|c|c|c|c|}
\hline \multicolumn{5}{|l|}{ TABLE 5} \\
\hline \multicolumn{5}{|c|}{ DEPENDANT VARIABLE : RMS } \\
\hline VARIABLES & COEFFICIENTS & $t$ value & COEFFICIENTS & t value \\
\hline CONSTANT & $\underline{4.6235}$ & 1.704 & 5.0718 & 2.609 \\
\hline $\mathrm{L}(\mathrm{S})$ & -0.30305 & -1.595 & -0.3358 & -2.464 \\
\hline VI & $-\underline{-5.1251}$ & -1.907 & -6.5764 & -2.749 \\
\hline ADI & 11.774 & 1.249 & 12.217 & 1.334 \\
\hline RDI & -9.4767 & -0.246 & -15.915 & -0.622 \\
\hline LRI & -75.999 & -2.400 & -76.682 & -2.458 \\
\hline FE & -0.01668 & -1.408 & -0.01842 & -2.112 \\
\hline MKI & -15.421 & -2.425 & -15.177 & -2.401 \\
\hline MCI & 10.984 & 6.235 & 10.842 & 6.597 \\
\hline SKILL & -0.1492 & -0.245 & & \\
\hline AGE & -0.10684 & -1.460 & $\underline{-0.11406}$ & -1.774 \\
\hline FER & 1.0015 & 0.576 & 1.2921 & 1.136 \\
\hline LRR & 8596.0 & 2.307 & $\mathbf{8 7 0 3 . 7}$ & 2.379 \\
\hline MKR & 2608.4 & 2.445 & 2562.8 & 2.421 \\
\hline D86 & -2.4844 & -0.845 & -2.2223 & -0.950 \\
\hline $\mathbf{L}(\mathrm{S}) \mathrm{D}$ & 0.0231 & 0.098 & 0.0595 & 0.250 \\
\hline VID & 9.6834 & 2.371 & 10.161 & 2.798 \\
\hline $\mathrm{ADD}$ & -32.88 & -1.596 & -48.867 & -2.449 \\
\hline $\mathrm{RDD}$ & 209.83 & 2.641 & 212.58 & 2.740 \\
\hline LRD & 111.3 & 3.181 & 102.24 & 3.041 \\
\hline FED & 0.01303 & 0.753 & 0.0141 & 0.874 \\
\hline MKD & 49.229 & 3.473 & 44.239 & 3.216 \\
\hline MCD & -9.122 & -4.572 & -9.1547 & -4.749 \\
\hline SKD & 1.8581 & 1.320 & & \\
\hline AGD & -8.1414 & -2.162 & -8.4475 & -2.082 \\
\hline FERD & 7.9161 & 1.629 & 5.7748 & 1.345 \\
\hline LRRD & -55633 & -3.087 & -46084 & -2.923 \\
\hline MKRD & -37013 & -3.575 & -39508 & -3.413 \\
\hline R SQR & 0.8299 & & 0.8199 & \\
\hline Adj. R SQR & 0.7343 & & 0.7298 & \\
\hline F & 8.676 & & 9.103 & \\
\hline NOBS & 76 & & 76 & \\
\hline
\end{tabular}

Notes:

(i) Coefficients printed in bold are significant at 0.05 or higher level and those underlined are significant at 0.10 level in two tailed test (ii) Variables which ends with " $D$ " are the slope dummies for the post de-regulation period. 


\begin{tabular}{|lccccc|}
\hline \multicolumn{7}{|l|}{ TABLE - 6: ESTIMATED SIGNS AND CO-EFFICIENT VALUES } & \multicolumn{2}{l|}{ POST DE-REGULATION } \\
\hline \multicolumn{2}{|l}{ VARIABLES } & PRE DE-REGULATION & CO-EFFICIENT & SIGN & CO-EFFICIENT \\
\hline \multicolumn{7}{l}{ V1 } & SIGN & 6.5764 & + & 3.5844 \\
LRI & - & 76.682 & + & 25.563 \\
MKI & - & 15.177 & + & 29.061 \\
MCI & - & 10.842 & + & 1.6877 \\
AGE & + & 0.11406 & - & 8.5616 \\
LRR & - & 8703.7 & - & 37380 \\
MKR & + & 2562.8 & - & 36945 \\
& + & & & \\
\hline
\end{tabular}

Note: These coefficient values are taken from the estimated equation presented in column 3 of Table 5. The actual values for post de-regulation period was obtained by adding the estimated coefficients for slope dummies with that of the variables. 


\section{Abbreviations of Firms}

$\begin{array}{lll}\text { ASHLEY } & - & \text { ASHOK LEYLAND LIMITED } \\ \text { BAJAJ } & - & \text { BAJAJ TEMPO LIMITED } \\ \text { DCMTOY } & - & \text { DCM TOYOTA LIMITED } \\ \text { EIMOROR } & - & \text { EICHER MOTORS LIMITED } \\ \text { HMOTOR } & - & \text { HINDUSTAN MOTORS LIMITED } \\ \text { MAHINDRA } & - & \text { MAHINDRA AND MAHINDRA LIMITED } \\ \text { MAHNISSAN } & - & \text { MAHINDRA NISSAN LIMITED } \\ \text { MARUTI } & - & \text { MARUTI SUZUK1 LIMITED } \\ \text { PREMIER } & - & \text { PREMIER AUTOMOBILES LIMITED } \\ \text { SMOTOR } & - & \text { STANDARD MOTOR PRODUCTS OF INDIA LIMITED } \\ \text { SWAMAZ } & - & \text { SWARAJ MAWA LIMITED } \\ \text { TELCO } & - & \text { TATA ENGINEERING AND LOCOMOTIVES COMPANY } \\ & & \end{array}$


References

Archibugi, Daniele and Jonathan Michie (1995):'The Globalisation of Technology: a new Taxonomy', Cambridge Journal of Economics, 19 121-40.

Bonaccorsi, Andrea (1992) :'On the Relationship between Firm Size and Export Intensity" Journal of International Business Studies. 23 (4), 605-35.

Buckley, Peter J., John H. Dunning and Robert D. Pearce (1978):'The influence of firm size, industry, degree of multinationality on the growth and profitability of the world's largest firms 1962-72', Weltwirtschaftliches Archiv, 614, 243-57.

Cohen, Wesley M. and Daniel A. Levinthal (1989):'Innovation and Learning: The Two Faces of R \& D', Economic Journal. 99, 569-96.

Cooper, C. (1991) :'Are Innovation Studies on Industrialised Economies Relevant to Technology Policy in Developing Countries', UNU/INTECH Working paper NO. 3, Maastricht.

Dasgupta, Ajit and N.S. Siddharthan (1985):'Industrial Distribution of Indian Exports and Joint Ventures AbroaX, Development and Change, 16, 15 9-74.

D'Costa, Anthony P. (1995) :'The restructuring of the Indian automobile industry: Indian state and Japanese Capital', World Development, 23 (3), 485-502.

Dosi, Giovanni (1988):'Sources, Procedures and microeconomic effects of innovation', Journal of Economic Literature, 26 (3), 1120-71.

Keith Pavitt and Luc Soete (1992):'The Economics of Technical Change and International Trade', London, Harvester - Wheatsheaf.

Dunning, John H. (1993): Multinational Enterprises and the Global Economy, AddisonWesley, Workingham, England.

Greene, W. (1993): Econometric Analysis, 2nd Edition Macmillan.

Hirsch. S. and Z. Adar (1974) :'Firm Size and Export Performance', World Development, 2 (7), 41-46.

Kathuria, Sanjay (1996) :Competing Through Technology and Manufacturing Strategy: A Study of the Indian Commercial Vehicles Industry, New Delhi, Oxford University Press.

Katz, J.M. (1984) :'Domestic Technological Innovation and Dynamic Comparative Advantage' Journal of Development Economics, 16 13-27. 
Kumar, N. (1990) : Multinational enterprises in India: Industrial Distribution, Characteristics and Performance, London and New York, Routledge.

Kumar, N. and N.S.Siddharthan (1994):'Technology, Firm Size and Export Behaviour in Developing Countries: The Case of Indian Enterprises', The Journal of Development Studies, 31 (2), 289-309.

Lall, Sanjaya (1986) :'Technological Development and Export Performance in LDCs:Leading Engineering and Chemical Firms in India', Weltwirtschaftliches Archiv, 122 (1), 8 0-9 1.

Metcalfe, J.S. (1995) :7echnology systems and technology policy in an evolutionary framework', Cambridge Journal of Economics, 19, 25-46.

Narayana, D. (1989) :'The Motor Vehicle Industry in India', Trivandrum, Center for Development studies.

Narayanan, K. (1988) :'In-house R \& D and Imported Technology in Indian Automobile Industry', M.Phil Thesis, Delhi School of Economics, Delhi University, Delhi.

Posner, Michael V. (1961) :'International Trade and Technical Change', Oxford Economic Papers, 13, 11-37.

Schumpeter, Joseph A. (1943) : 'Capitalism, Socialism and Democracy', London, Guye Allan and Unwin.

Siddharthan, N.S. and S.Lall (1982): 'The recent growth of largest U.S. Multinationals', Oxford Bulletin of Economics and Statistics, 44, 1-13.

Siddharthan, N.S., B.L.Pandit and R.N.Agarwal (1994):'Growth and Profit behaviour of large scale Indian firms', The Developing Economies, 32, 188-209.

Soete, Luc (1981) :'A General Test of Technological Gap Theory', Weltwirtschaftliches Archiv, 117, 638-59.

Vernon, R. (1966) :'International Investment and International Trade in the Product Life Cycle', Quarterly Journal of Economics, 80, 190-207.

Williamson, Oliver E. (1985) :The Economic Institutions of Capitalism, The Free Press, New York.

Willmore, L. (1992) :7ransnationals and Foreign Trade: Evidence from Brazil', The Journal of Development Studies, 28 (2), 314-35. 